\title{
Ovarian carbonyl reductase activity in rats at persistent oestrus
}

\author{
N. Inazu and T. Fujii \\ Department of Pharmacology, Teikyo University School of Medicine, 2-11-1 Kaga, Itabashi-ku, \\ Tokyo 173, Japan
}

\begin{abstract}
Age-related changes and effects of gonadotrophins on ovarian carbonyl reductase (CR) of virgin female Wistar-Imamichi rats were investigated. In mature rats ovarian $C R$ is an LH-dependent oxidoreductase and is closely involved in the periovulatory process. After 8 months of age, all of the rats exhibited persistent oestrus and the ovarian mass was significantly decreased, whereas 4- and 5-month-old rats showed the regular 4 day oestrous cycles and ovulation occurred. The ovarian CR activity towards four substrates declined steeply consistent with persistent oestrus and the enzyme activity for each substrate at 15 months of age was $1.4-53.7 \%$ lower than at 4 months of age. The ovarian CR concentration measured by western blot analysis was also lower at 8 months of age. Equine chorionic gonadotrophin (eCG) and hCG were administered to 10- and 15-month-old rats at persistent oestrus to examine whether the ovarian $C R$ in rats at persistent oestrus is influenced by gonadotrophins. Treatment with hCG not only increased ovarian CR activity and its concentration but also caused ovulation at both ages. The immunoreactivity to anti-ovarian CR antibody in the theca cells of the hCG-treated ovary was greater than that of the control ovary. Equine(e) CG did not stimulate ovarian CR activity in rats at persistent oestrus, although ovarian mass of 10-month-old rats was increased after administration of 50 iu of eCG. These results indicate that changes in ovarian CR with ageing are related to the transition of regular oestrous cyclicity to acyclicity and that the expression of ovarian CR markedly decreased in aged rats is stimulated by hCG.
\end{abstract}

\section{Introduction}

Carbonyl reductase (CR) (EC 1.1.1.184), 9-keto-prostaglandin reductase, is a cytosolic and monomeric oxidoreductase that catalyses the NADPH-dependent reduction of a variety of endogenous and xenobiotic carbonyl compounds (Wermuth, 1985). We have purified and characterized CR from ovary (Iwata et al., 1989), testis (Iwata et al., 1990a) and adrenal gland (Inazu et al., 1994) of rats and human testis (Inazu et al., 1992a). In rats, $C R$ is expressed specifically in the gonads and adrenal glands (Iwata et al., 1989, 1990a, 1990b).

The decline in reproductive functions with ageing in mammals is known to occur earlier in the lifespan of most females than in males (Meites, 1982; Scarbrough and Wise, 1990; Rubin, 1992). This is characterized by constant cornified vaginal smears, the presence of well-developed follicles in the ovary, and the lack of a preovulatory LH surge (Rubin et al., 1984). Deficits at the hypothalamus are believed to play an important role in the persistent vaginal oestrus of ageing female rats, although reproductive decline is a complex process of the hypothalamo-pituitary-ovarian axis including pituitary response to gonadotrophin releasing hormone $(\mathrm{GnRH})$ and ovarian response to gonadotrophins (Meites, 1982). However, detail of the mechanism of reproductive senescence in each component of the axis is not clear.
The present study was undertaken to investigate age-related changes in ovarian CR in relation to oestrous cyclicity of rats. In addition, the effects of gonadotrophins on the ovarian $\mathrm{CR}$ in rats at persistent oestrus in which circulating oestrogen is chronically increased without the positive feedback mechanism (Matt et al., 1987) were examined by administering hCG and equine chorionic gonadotrophin (eCG) to 10 - and 15-month-old Wistar-Imamichi rats at persistent oestrus and evaluating changes in the ovarian CR biochemically and immunohistochemically.

\section{Materials and Methods}

\section{Animals}

Virgin female Wistar-Imamichi rats were purchased from the Institute for Animal Reproduction (Ibaragi) and maintained in a temperature-controlled $\left(24^{\circ} \mathrm{C}\right)$ room under a $12 \mathrm{~h}$ light: $12 \mathrm{~h}$ dark cycle with lights on at 06:00 h. Food and water were always available. The oestrous cyclicity was monitored by obtaining daily vaginal smears and rats that exhibited regular 4 day oestrous cycles up to 5 months of age were used for the experiments. The oestrous cycles in Wistar-Imamichi rats are longer after 6 months of age, and the ovarian CR activity in rats that do not have the regular 4 day oestrous cycles is very low compared with that in cyclic rats (N. Inazu and T. Fujii, 
unpublished). Four- and five-month-old rats were killed at 08:00-09:00 $\mathrm{h}$ on the day of oestrus and 8-, 10- and 15-monthold rats were killed at 08:00-09:00 $\mathrm{h}$ after vaginal smears contained cornified cells for at least 10 consecutive days.

\section{Experimental protocol}

Gonadotrophin treatment. Equine (e) CG and hCG were purchased from Teikoku Hormone Mfg (Tokyo) and dissolved in $0.9 \%(\mathrm{w} / \mathrm{v})$ saline solution. hCG (25 iu) was given s.c. to $10-$ and 15-month-old rats at persistent oestrus at 15:00 $\mathrm{h}$ and the ovaries were isolated at $18 \mathrm{~h}$ after hCG treatment. eCG (25 iu and $50 \mathrm{iu}$ ) were given s.c. to 10 -month-old rats at persistent oestrus and 15-month-old rats at persistent oestrus were administered 50 iu eCG s.c. The ovaries were isolated $72 \mathrm{~h}$ after eCG treatment.

Enzyme preparation. The ovaries of each rat were isolated immediately and homogenized in $8 \mathrm{ml}$ of phosphate buffer $\left(0.01 \mathrm{~mol} 1^{-1}, \mathrm{pH} 6.5\right)$ containing $1.15 \%(\mathrm{w} / \mathrm{v}) \mathrm{KCl}$, dithiothreitol $\left(1 \mathrm{mmol} \mathrm{l}^{-1}\right)$ and EDTA $\left(0.5 \mathrm{mmol} \mathrm{l}^{-1}\right)$. The ovarian homogenate was centrifuged at $105000 \mathrm{~g}$ for $60 \mathrm{~min}$ at $4^{\circ} \mathrm{C}$ by a Hitachi Centrifuge Model CP 70G. The $105000 \mathrm{~g}$ supernatant (cytosolic fraction) was used for the enzyme activity as a crude enzyme preparation. Oviducts of each rat were examined under a dissecting microscope for the presence of ova.

Carbonyl reductase assay. The activity of carbonyl reductase was determined spectrophotometrically using 4-nitroacetophenone ( $1 \mathrm{mmoll}^{-1}$, PNAP), 4-nitrobenzaldehyde (1 mmol l-1, PNBA), menadione $\left(0.2 \mathrm{mmol} \mathrm{l}^{-1}\right)$ or 4 benzoylpyridine ( $1 \mathrm{mmol} \mathrm{I}^{-1}, 4 \mathrm{BP}$ ) as substrate. The standard assay mixture consisted of ovarian cytosol, substrate, NADPH $\left(0.1 \mathrm{mmol} \mathrm{l}^{-1}\right)$ and phosphate buffer $\left(0.1 \mathrm{~mol} \mathrm{l}^{-1}\right.$, $\mathrm{pH} 6.5$ ) in a total volume of $1.0 \mathrm{ml}$. One unit of the enzyme was defined as the amount that catalysed oxidation of $1 \mu \mathrm{mol}$ $\mathrm{NADPH}$ at $340 \mathrm{~nm}$. Total protein in the cytosolic fraction was determined by the method of Lowry et al. (1951) using BSA as a standard.

Quantitation of carbonyl reductase. Carbonyl reductase in rat ovarian cytosol was quantified by western blot analysis according to Inazu et al. (1990a). Briefly, samples (ovarian cytosol) and standard (purified ovarian CR, CR2) were subjected to SDSPAGE $(10 \%$ gel), and proteins were electroblotted onto polyvinylidene difluoride membrane (Clear Blot Membrane, Atto Co., Tokyo). The enzyme protein on the membrane was detected by peroxidase-antiperoxidase (PAP) staining with anti-ovarian CR2 antiserum and scanned with a densitometer (CS-9000, Shimadzu, Kyoto). The peak area of each sample and standard was calculated, and the ovarian CR concentration was expressed in $\mu \mathrm{g} \mathrm{mg}^{-1}$ protein of cytosolic fraction.

Immunohistochemical method. The ovaries of each rat treated with hCG at 10 and 15 months of age were quickly isolated, immediately immersed in sodium phosphate buffered (0.1 mol l-1, $\mathrm{pH} \mathrm{7.4)} 4 \%(\mathrm{w} / \mathrm{v})$ paraformaldehyde and fixed for $24 \mathrm{~h}$. After fixation, the samples were rinsed in sodium phosphate buffer $\left(0.1 \mathrm{~mol} \mathrm{l}^{-1}, \mathrm{pH} 7.4\right)$, sequentially dehydrated in ethanol solution $(70-100 \%, v / v)$, and embedded in paraffin wax. The paraffin wax blocks were cut into $4 \mu \mathrm{m}$ thick slices with a rotary microtome and the immunohistochemical staining with anti-ovarian CR2 antiserum was carried out by the avidin-biotin peroxidase complex $(A B C)$ method with a Vectastain ABC kit (Vector Lab., USA) (Inazu et al., 1990b; Iwata et al., 1990c).

\section{Chemicals}

NADPH was obtained from Oriental Yeast Co. (Tokyo). PNAP, PNBA, menadione, 4BP, dithiothreitol and EDTA were purchased from Wako Pure Chemical Co. (Osaka). Other chemicals of reagent grade were obtained from Bio-Rad Co. (Tokyo) and Wako Pure Chemical Co.

\section{Statistical analysis}

All results were expressed as the mean \pm SEM of four-eight rats. Duncan's multiple range test was used for comparison between groups, with $P$ values of 0.05 or less considered to indicate a significant difference.

\section{Results}

\section{Age-related changes in ovarian carbonyl reductase}

Four- and five-month-old Wistar-Imamichi rats showed regular 4-day oestrous cycles and ovulation occurred, whereas after 8 months of age the rats were at persistent oestrus and ovarian mass had markedly declined (Table 1 ). The ovarian $C R$ concentration determined by western blot-PAP analysis was very low in rats at persistent oestrus, and this decrease in the $\mathrm{CR}$ concentration was associated with lack of the regular 4 day oestrous cycles (Table 1 and Fig. I).

The activity of $C R$ at 4 and 5 months of age, the age at which rats have the regular 4 day oestrous cycles, was high (Fig. 2). However, after 8 months of age, the age at which rats exhibited persistent oestrus, CR activity was significantly lower, that is, PNAP reduction was decreased to $47.7 \%$ at 8 months of age, to $14.3 \%$ at 10 months of age and to $1.4 \%$ at 15 months of age of 4-month-old values; PNBA reduction to $51.9,19.3$ and $10.5 \%$, respectively; menadione reduction to $65.9,38.1$ and $53.7 \%$, respectively, $4 \mathrm{BP}$ reduction to $32.6,26.3$ and $6.6 \%$, respectively. The changes in $4 \mathrm{BP}$ reducing activity which reflect rat ovarian CR activity accurately (Iwata et al., 1989; Iwata et al., 1990c) correlated well with the changes in ovarian CR concentration with ageing $(y=1.15 x-5.68$, $r=0.989$ ).

\section{Effects of gonadotrophins on ovarian carbonyl reductase}

In 10-month-old rats at persistent oestrus, the ovarian mass was increased by 1.7 times compared with control values by hCG treatment, and ovulation occurred (Table 2). Similarly, the ovarian mass in 15 -month-old rats at persistent oestrus was increased to 1.8 times the control values by hCG, and 
Table 1. Age-related changes in body mass, ovarian mass and ovarian carbonyl reductase (CR) concentration in rats in relation to ovulation

\begin{tabular}{ccccc}
\hline $\begin{array}{c}\text { Age }(n) \\
\text { (months) }\end{array}$ & $\begin{array}{c}\text { Body mass } \\
(\mathrm{g})\end{array}$ & $\begin{array}{c}\text { Ovarian mass } \\
(\mathrm{mg})\end{array}$ & $\begin{array}{c}\text { Number } \\
\text { of ova }\end{array}$ & $\begin{array}{c}\text { CR concentration } \\
\left(\mu \mathrm{g} \mathrm{mg} \text { m }^{-1} \text { protein }\right)\end{array}$ \\
\hline $4(5)$ & $287.0 \pm 7.73$ & $144.2 \pm 12.11$ & $13 \pm 0.8$ & $21.95 \pm 1.622$ \\
$5(6)$ & $324.3 \pm 10.89^{*}$ & $136.3 \pm 5.19$ & $15 \pm 0.9$ & $25.92 \pm 2.382$ \\
$8(5)$ & $340.2 \pm 18.92^{*}$ & $77.0 \pm 6.80^{* *}$ & - & $10.68 \pm 0.584^{* * *}$ \\
$10(5)$ & $440.2 \pm 22.92^{* * *}$ & $65.4 \pm 12.37^{* *}$ & - & $8.51 \pm 1.125^{* *}$ \\
$15(4)$ & $458.3 \pm 35.56^{*}$ & $54.5 \pm 3.12^{* *}$ & - & $7.74 \pm 0.620^{* *}$ \\
\hline
\end{tabular}

Each value shows the mean \pm SEM. ${ }^{*} P<0.05 ;{ }^{* *} P<0.01 ; * * P<0.001$ : significantly different from 4 -month-old rats. ${ }^{a}$ Not ovulated.

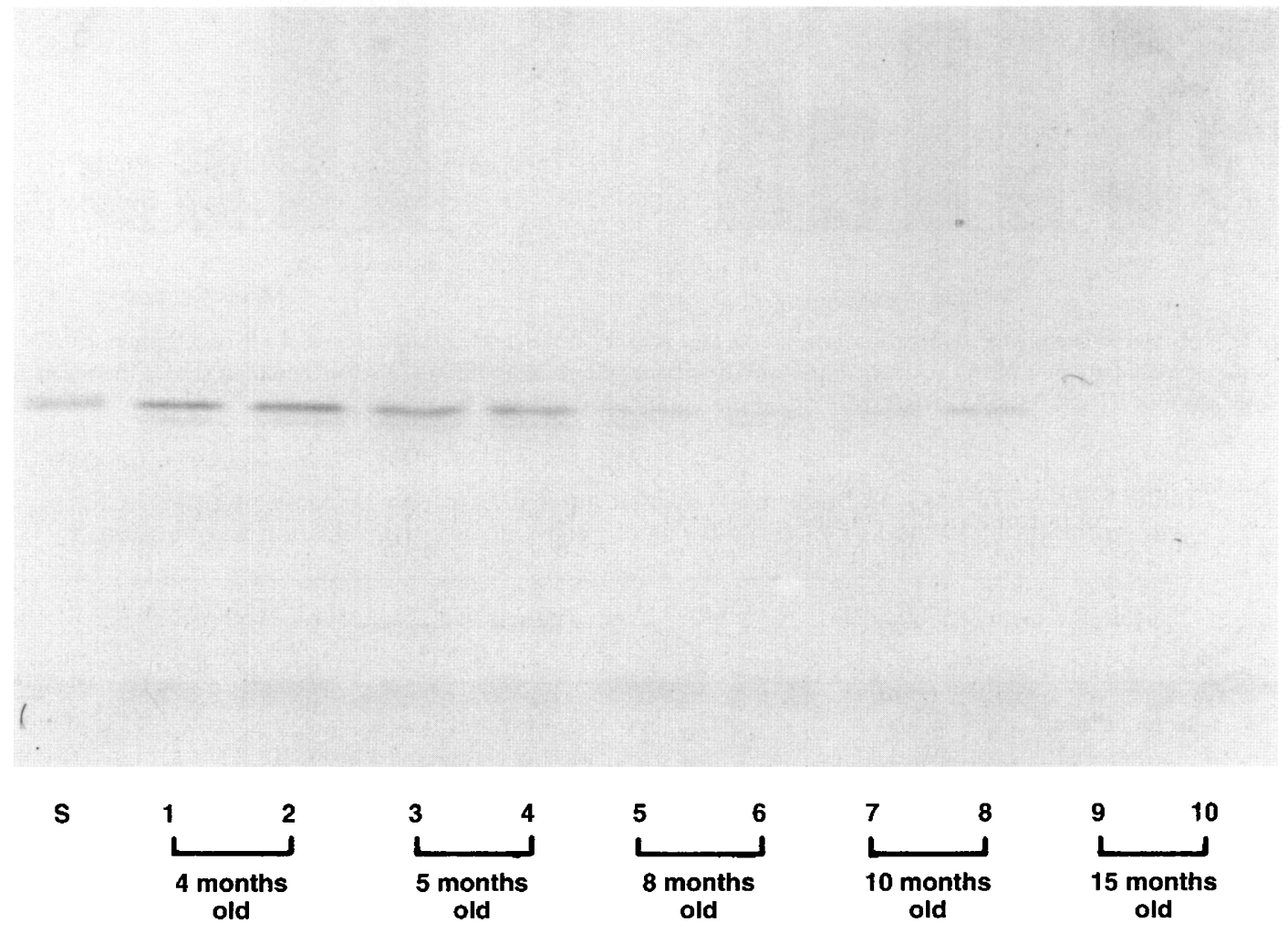

Fig. 1. Western blot analysis of ovarian cytosol from rats at various ages. Each lane contained $1 \mu \mathrm{g}$ of cytosolic protein. S: purified rat ovarian carbonyl reductase (18.2 $\mathrm{ng}$ ).

ovulation occurred, although there were few ova between 2 and 9 months of age compared with the numbers in 10-month-old hCG-treated animals. However, the increase in the ovarian CR concentration after hCG treatment was different between 10-month-old rats at persistent oestrus and 15-month-old rats at persistent oestrus. In 10-month-old rats, the $C R$ concentration was increased (3.8-fold) to $40.54 \mu \mathrm{g} \mathrm{mg}^{-1}$ from $10.77 \mu \mathrm{g} \mathrm{mg}^{-1}$ of control, whereas in 15-month-old rats, the magnitude of the increase and the number of ova were low.

In 10-month-old rats at persistent oestrus, both PNAP and PNBA reducing activities fluctuated and did not change after hCG treatment (Fig. 3). Both menadione and $4 \mathrm{BP}$ reducing activities were significantly increased by $\mathrm{hCG}$, and $4 \mathrm{BP}$ reducing activity, which reflects the rat ovarian $C R$ activity, was increased to 2.3 -fold of control values. In 15-month-old rats at persistent oestrus, three reducing activities (of PNAP, menadione and $4 \mathrm{BP}$ ), but not that of PNBA, were significantly increased by $\mathrm{hCG}$, and $4 \mathrm{BP}$ reducing activity was increased (4.2-fold) to $15.45 \mathrm{mU} \mathrm{mg}^{-1}$ from $3.67 \mathrm{mU} \mathrm{mg}^{-1}$ of control after hCG. However, PNAP reducing activity in two of six control rats was not detectable at 15 months of age.

In both controls, well-developed follicles, which are characterized in the ovaries of rats at persistent oestrus (Rubin et al., 1984), were observed, and immunoreactivity to anti-CR2 antibody was negative or very weak in the theca interna cells and interstitial gland cells (Fig. 4). The theca interna cells of ovaries of 10- and 15-month-old rats that were treated with 
(a)
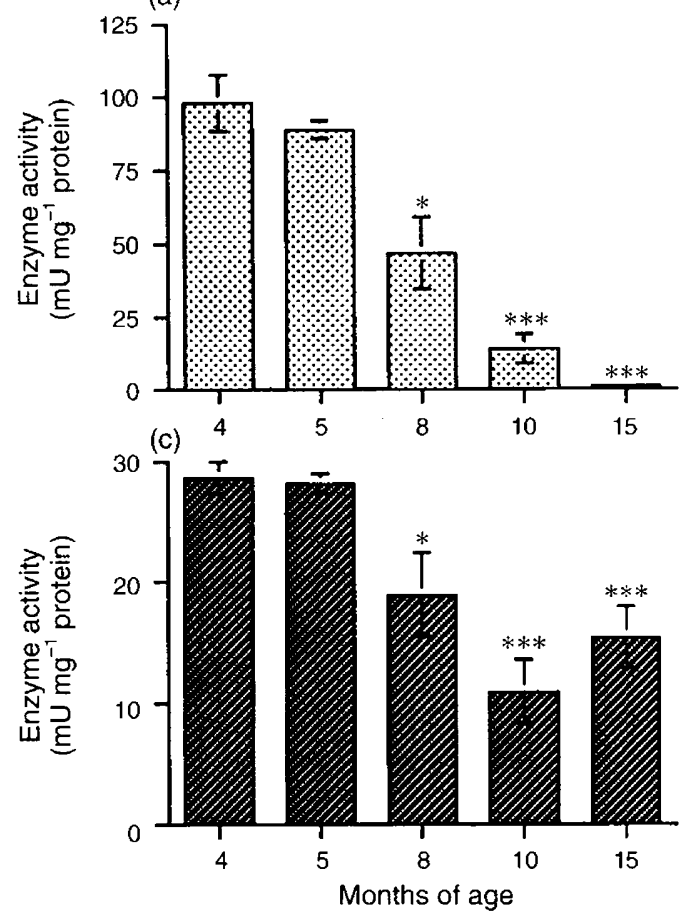

(b)

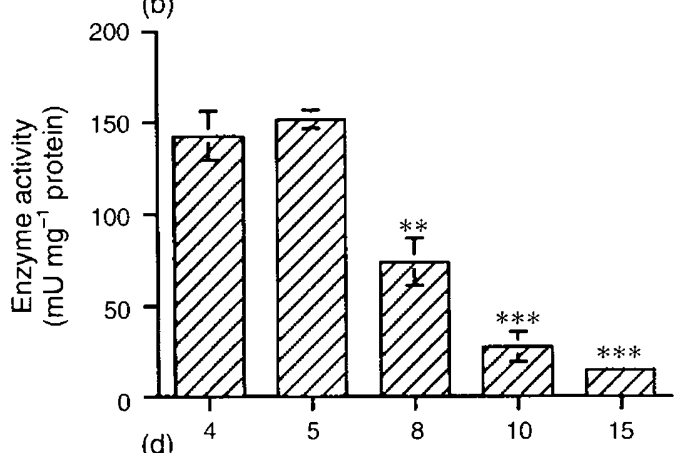

(d)

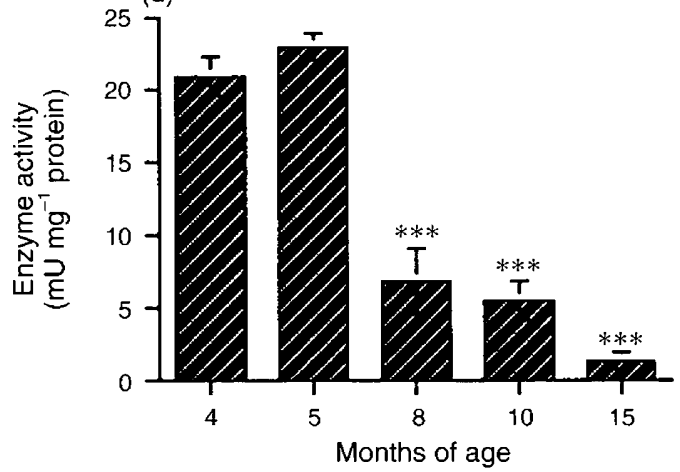

Fig. 2. Age-related changes in ovarian carbonyl reductase activity towards four substrates (a) 4-nitroacetophenone (PNAP), (b) 4-nitrobenzaldehyde (PNBA), (c) menadione and (d) 4-benzoylpyridine (4BP) in rats. Each column shows the mean \pm SFM of four-six rats. $* P<0.05 ; * * P<0.01 ; * * P<0.001$ : significantly different from 4 -month-old rats.

Table 2. Effects of hCG on body mass, ovarian mass and ovarian carbonyl reductase (CR) concentration in 10- and 15 -month-old rats at persistent oestrus in relation to ovulation

\begin{tabular}{lcccc}
\hline $\begin{array}{l}\text { Animals } \\
(n)\end{array}$ & $\begin{array}{c}\text { Body mass } \\
(\mathrm{g})\end{array}$ & $\begin{array}{c}\text { Ovarian mass } \\
(\mathrm{mg})\end{array}$ & $\begin{array}{c}\text { Number } \\
\text { of ova }^{2}\end{array}$ & $\begin{array}{c}\text { CR concentration } \\
\left(\mu \mathrm{g} \mathrm{mg}^{-1} \text { protein }\right)\end{array}$ \\
\hline $\begin{array}{l}10 \text { months old } \\
\text { Control (6) }\end{array}$ & $340.8 \pm 15.46$ & $73.8 \pm 6.39$ & - & $10.77 \pm 1.418$ \\
$\quad$ hCG (5) & $322.0 \pm 9.02$ & $125.0 \pm 9.64^{* *}$ & $11 \pm 0.6$ & $40.54 \pm 2.715^{* * *}$ \\
15 months old & & & - & $3.76 \pm 0.150$ \\
$\quad$ Control (6) & $386.0 \pm 16.13$ & $48.5 \pm 4.86$ & $4 \pm 1.0$ & $8.48 \pm 0.493^{* *}$ \\
hCG (7) & $420.6 \pm 24.76$ & $86.9 \pm 4.70^{* *}$ & & \\
\hline
\end{tabular}

Rats were given 25 iu hCG s.c. at 15:00 h and the ovaries were isolated $18 \mathrm{~h}$ after the treatment. Each value shows the mean \pm SEM. ${ }^{* *} P<0.01 ; * * * P<0.001$ : significantly different from control.

${ }^{\text {a }}$ Not ovulated.

hCG were strongly immunostained compared with controls, although immunostaining of the interstitial gland cells was weak. However, the granulosa cells did not stain.

The ovarian mass was significantly increased by treatment with 50 iu eCG in 10-month-old rats at persistent oestrus, but not with 25 iu of eCG, although neither 25 iu nor 50 iu of eCG caused ovulation (Table 3). In addition, the ovarian $\mathrm{CR}$ concentration was also increased by 50 iu eCG but not significantly, whereas the stimulatory ratio of the concentration by eCG was weaker than that by hCG. However, the stimulatory effects of eCG on the ovarian mass and the ovarian $\mathrm{CR}$ concentration were not observed in 15-month-old rats.

Both PNAP and PNBA reducing activities did not change after eCG treatment and there were considerable variations in 10-month-old rats at persistent oestrus. Both menadione and $4 \mathrm{BP}$ reducing activities were significantly increased only by 50 iu of eCG, in particular, 4BP reducing activity was increased to 2.7 -fold of control values. However, no significant change in ovarian CR activity was found in 15-month-old rats, and PNAP reducing activity was not detectable in seven of eight control rats and in two of four rats treated with eCG (50 iu).

\section{Discussion}

Rat ovarian $C R$ was shown to be localized in both the theca interna cells and interstitial gland cells which produce androgens, but not in the granulosa cells which produce oestrogens 
(a)
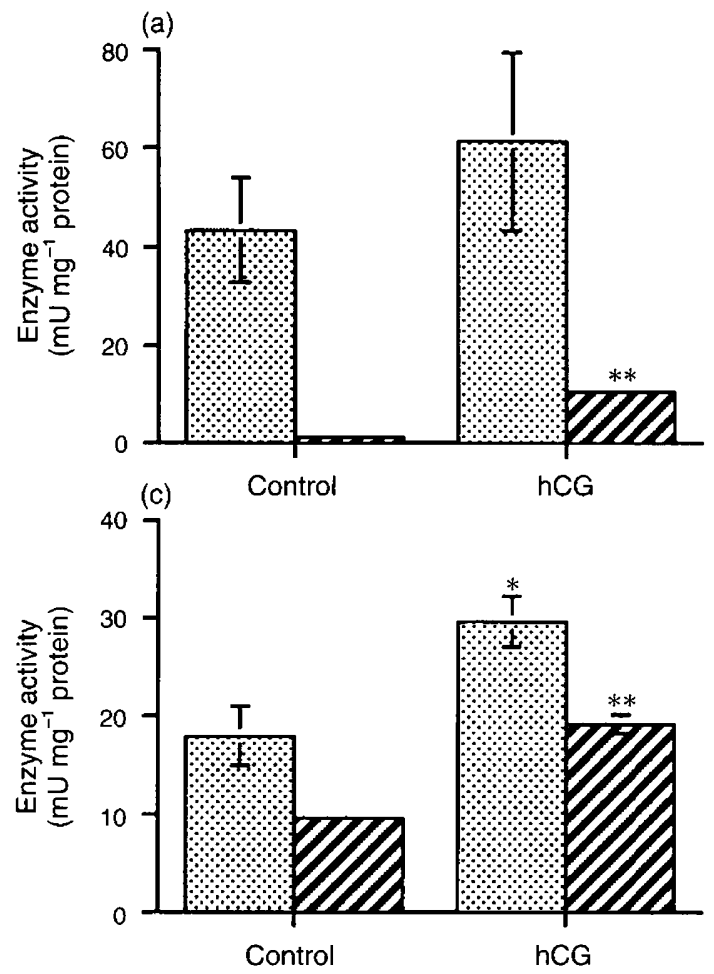

(b)
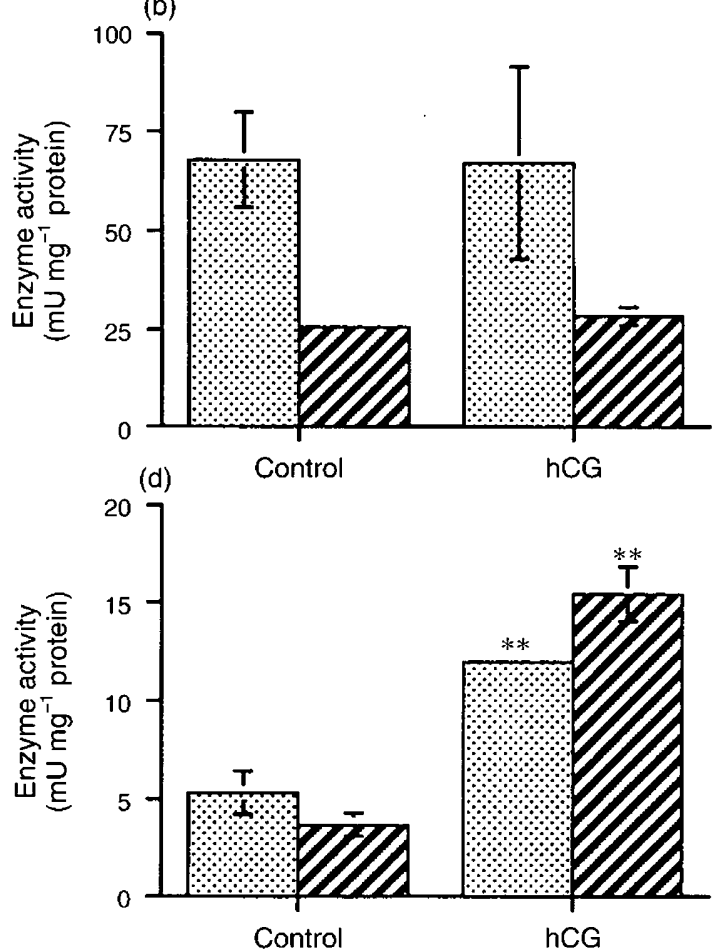

Fig. 3. Effects of hCG on ovarian carbonyl reductase activity towards four substrates (a) 4-nitroacetophenone (PNAP), (b) 4-nitrobenzaldehyde (PNBA), (c) menadione and (d) 4-benzoylpyridine (4BP) in 10- and 15-month-old rats at persistent oestrus. Rats were given 25 iu of hCG s.c. and the ovaries were isolated $18 \mathrm{~h}$ after the treatment. Each column shows the mean \pm SEM of five-seven rats. 10 months of age, 15 months of age. ${ }^{*} P<0.05,{ }^{*} P<0.01$ : significantly different from control.

(Inazu et al, 1989, 1990b) and LH/hCG was shown to induce CR in immature (Inazu et al., 1989, 1990b, 1992b) and young mature (Inazu et al., 1990c; Iwata et al, 1990c) rats. These findings indicate that ovarian $\mathrm{CR}$ is closely involved in the ovulatory cycle of female rats. Furthermore, oestrogen potentiates the stimulatory effect of $\mathrm{LH} / \mathrm{hCG}$ on ovarian CR activity and concentration in immature rats, and potentiation of oestrogen is mediated by the oestrogen receptor (Inazu et al., 1989, 1990a, 1992b).

In the present study, Wistar-Imamichi rats exhibited persistent oestrus after 8 months of age, and the ovarian CR activity and its concentration showed a marked decrease. Sixty to seventy per cent of 6- and 7-month-old rats show irregular cycles. Matt et al. (1987) concluded that circulating oestrogen is chronically increased in rats at persistent oestrus but the positive feedback mechanism in the hypothalamo-pituitary axis is unresponsive. Thus, a significant decrease in ovarian CR activity towards the four substrates and its concentration in rats at persistent oestrus after 8 months of age reveals that synthesis of the enzyme is not inhibited because of the lack of positive feedback mechanism of oestrogen in aged rats. As treatment with hCG caused the significant increase in $4 \mathrm{BP}$ reducing activity, which reflects the ovarian $\mathrm{CR}$ activity in rats (Iwata et al., 1989; Inazu et al., 1990c) and CR concentration in rats at persistent oestrus, the low ovarian CR activity and its low concentration in rats at persistent oestrus must be due to the lack of LH surge. PNAP, PNBA and menadione reducing activities were also decreased with ageing, although the reduction for these substrates in the rat ovary does not reflect the ovarian CR activity as shown by Iwata et al. (1989, 1990a) and Inazu et al. (1990c). However, the reducing activities for these three substrates are significantly decreased after three consecutive treatments with oestrogen in young mature rats and hCG treatment cannot restore these activities that are decreased by oestrogen (Inazu and Satoh, 1994a). These results suggest that the ovarian enzymes that catalyse the NADPHdependent reduction of PNAP, PNBA and menadione other than $C R$ are inhibited by oestrogen, which is chronically increased in rats at persistent oestrus. Both PNAP and PNBA reducing activities may be inhibited by oestrogen in rats at persistent oestrus, since neither of the activities were sensitive to gonadotrophins, although PNAP reducing activity was significantly increased by $\mathrm{hCG}$ in 15 -month-old rats at persistent oestrus. Menadione reducing activity appears to be regulated by oestrogen and LH in a similar way to $4 \mathrm{BP}$ reducing activity, although the decrease in menadione reducing activity with ageing was not significant compared with the other three reducing activities.

We have confirmed that hCG enhances positive immunoreactivity in the theca interna cells and interstitial gland cells of oestradiol-pretreated immature rat ovary (Inazu et al., 1989). The purified rat ovarian CR catalyses the NADPHdependent reduction of $5 \alpha$-androstane-3-ketosteroids, such as $5 \alpha$-dihydrotestosterone and $5 \alpha$-androstane-3,17-dione (Iwata 

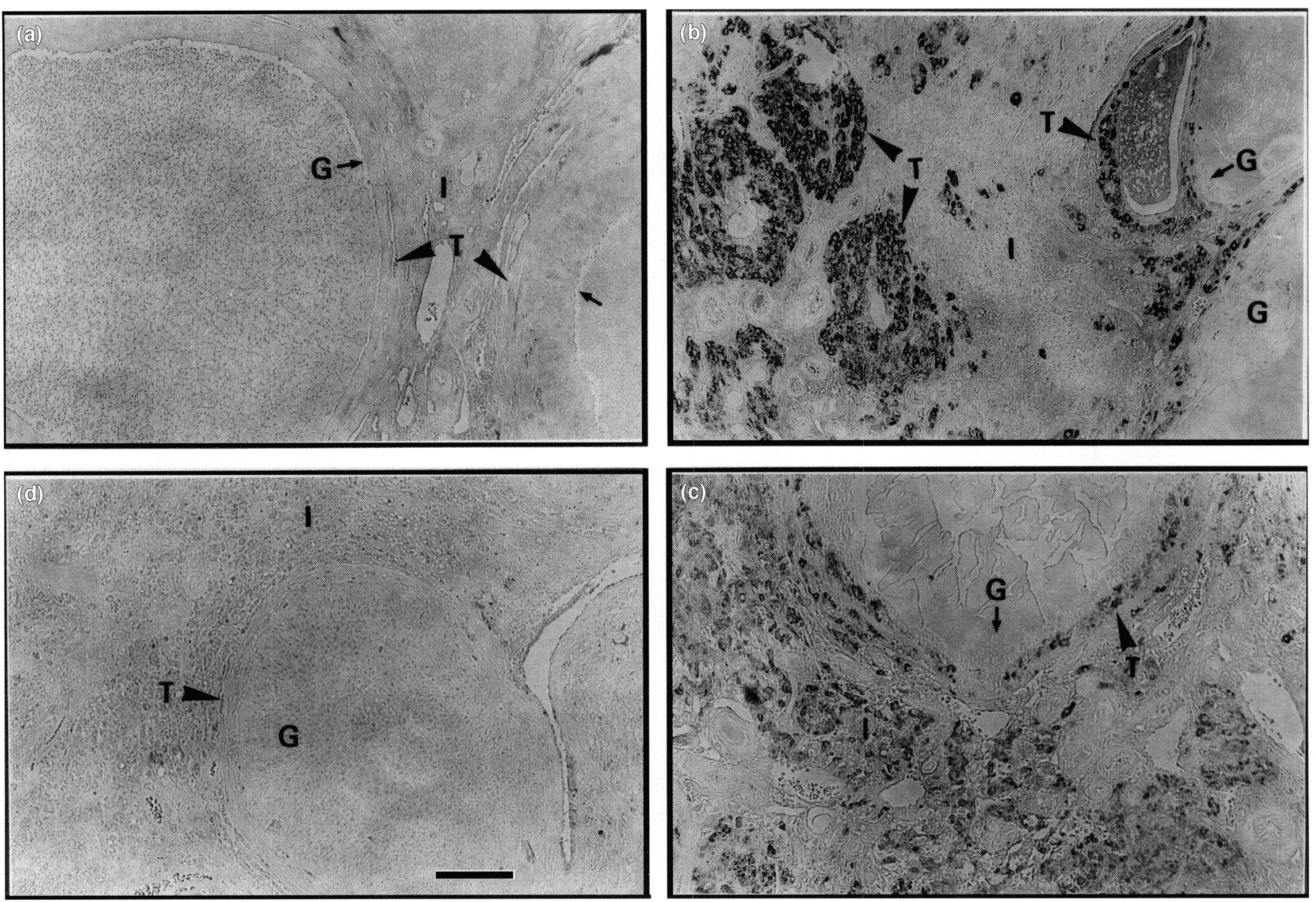

Fig. 4. Effect of hCG on immunohistochemical localization of ovarian carbonyl reductase in 10 - and 15 -month-old rats at persistent oestrus. T: theca interna cells; G: granulosa cells. 1: interstitial gland cells. Scale bar represents $400 \mu \mathrm{m}$.

Table 3. Effects of equine chorionic gonadotrophin (eCG) on body mass, ovarian mass and ovarian carbonyl reductase (CR) concentration in 10- and 15 -monthold rats at persistent oestrus

\begin{tabular}{lccr}
\hline $\begin{array}{l}\text { Animals } \\
(\mathrm{n})\end{array}$ & $\begin{array}{c}\text { Body mass } \\
(\mathrm{g})\end{array}$ & $\begin{array}{c}\text { Ovarian mass } \\
(\mathrm{mg})\end{array}$ & $\begin{array}{c}\text { CR concentration } \\
\left.(\mu \mathrm{g} \mathrm{mg})^{-} \text {protein }\right)\end{array}$ \\
\hline 10 months old & & & \\
$\quad$ Control (5) & $353.8 \pm 20.23$ & $74.4 \pm 8.70$ & $6.72 \pm 0.855$ \\
eCG 25 iu (4) & $346.8 \pm 10.94$ & $88.3 \pm 13.22$ & $6.46 \pm 0.555$ \\
eCG 50 iu (5) & $348.2 \pm 18.82$ & $127.2 \pm 6.49^{* *}$ & $14.44 \pm 4.238$ \\
15 months old & & & $4.56 \pm 0.129$ \\
Control (8) & $377.8 \pm 17.01$ & $43.4 \pm 2.15$ & $5.75 \pm 0.625$ \\
eCG 50 iu (4) & $407.0 \pm 9.54$ & $62.5 \pm 6.81$ & \\
\hline
\end{tabular}

Rats were given 25 and $50 \mathrm{iu}$ eCG s.c. at $0800 \mathrm{~h}$ and the ovaries were isolated $72 \mathrm{~h}$ after the treatment. Each value shows the mean \pm sev.

$* * P<0.0$ I: significantly different from control.

Ovulation was not observed in CCG-treated animals.

et al., 1989). However, physiological roles of 5( $\alpha$-3-olsteroids produced from $5 \alpha-3$-ketosteroids are not clear at present. Aono et al. (1981) reported that $5 u$-reductase, which produced $5 a$-androstane-3-ketosteroids and one of a variety of substrates for CR (Wermuth, 1985), is localized in the theca interstitial cells in immature rat ovary. These results suggest that ovarian $C R$, which is regulated by the hypothalamo--pituitary-ovarian axis, plays important roles in the androgen producing cells of 
(a)
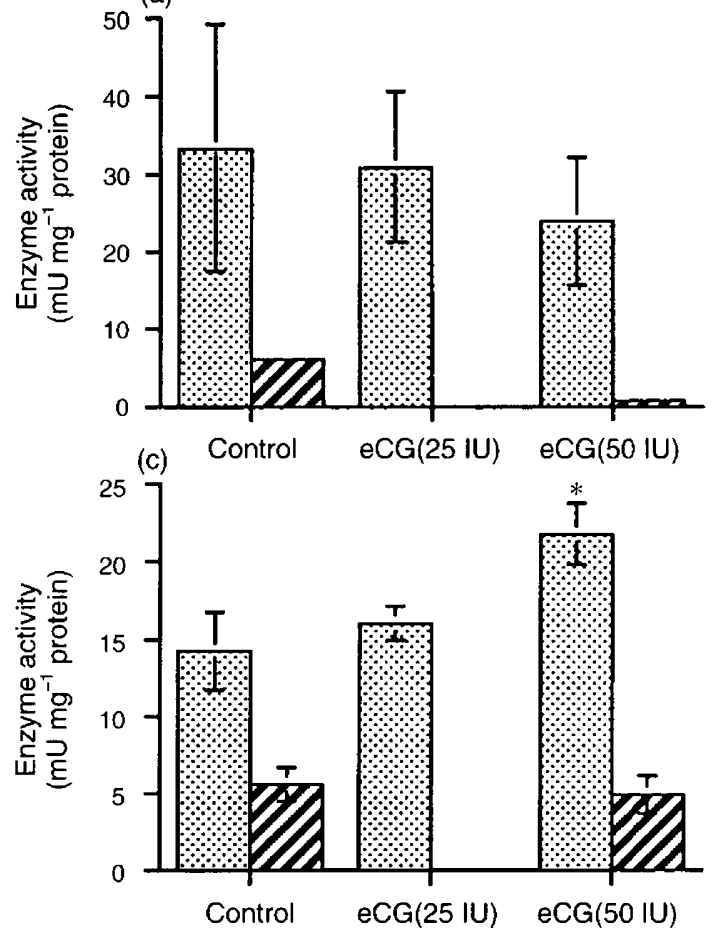

(b)
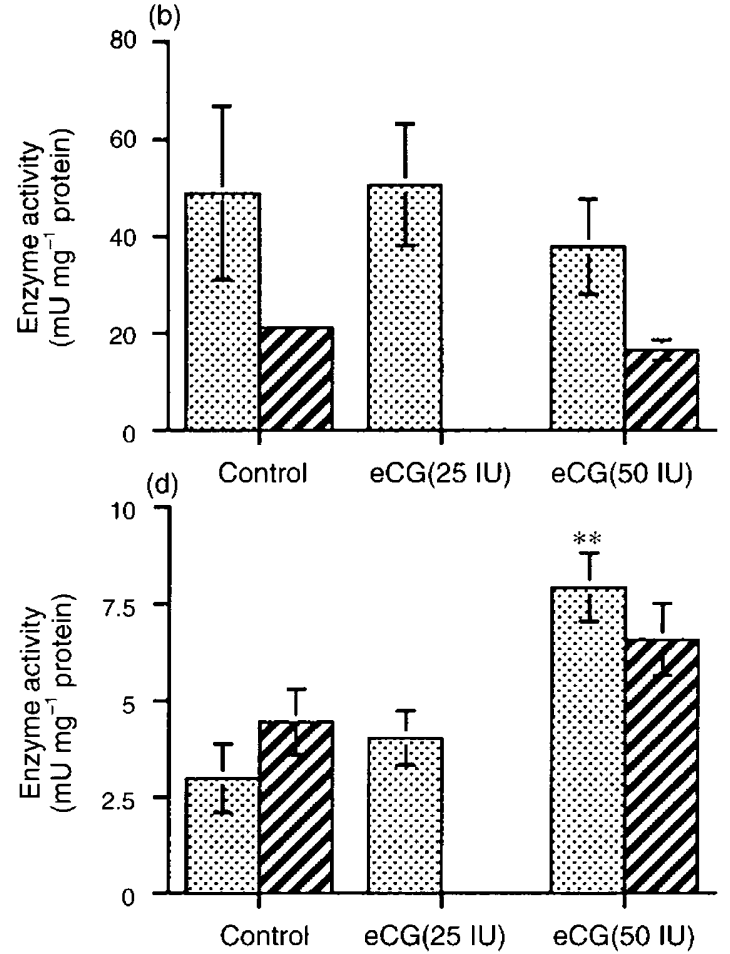

Fig. 5. Effects of equine chorionic gonadotrophin (eCG) on ovarian carbonyl reductase activity towards four substrates (a) 4-nitroacetophenone (PNAP), (b) 4-nitrobenzaldehyde (PNBA), (c) menadione and (d) 4-benzoylpyridine (4BP) in 10- and 15-month-old rats at persistent oestrus. Rats were given 25 or 50 iu eCG s.c. and the ovaries were isolated $72 \mathrm{~h}$ after the treatment. Each column shows the mean \pm SEM of four-eight rats. 10 months of age, 15 months of age. ${ }^{*} P<0.05$, $* * P<0.01$ : significantly different from control.

the ovary during the periovulatory process. In the study reported here, immunoreactivity with anti-CR2 antiserum in the theca interna cells and interstitial gland cells in rats at persistent oestrus (10 and 15 months of age) was negative or very weak, and hCG treatment increased immunoreactivity in these cells, particularly in the theca interna cells. We have reported that, although high doses of oestradiol inhibit the ovarian CR and ovulation, hCG activates the ovarian CR that is decreased by oestradiol treatment in mature cyclic rats without restoring the number of ova (Inazu and Satoh, 1994). Both the theca interna cells and interstitial gland cells express LH receptors and contain all the steroidogenic enzymes necessary to synthesize androgen which is converted to oestrogen in the granulosa cells. Rubin $e t$ al. (1984) and Merchenthaler $e t$ al. (1980) reported that hypothalamic GnRH is present in the neurones of aged rats at persistent oestrus in sufficient amounts to induce an LH surge, but the release of GnRH may be impaired in aged rats. Accordingly, the decline in the localization of ovarian $C R$ in aged rats at persistent oestrus is thought to be not only due to the high circulating oestrogen but also due to the lack of a preovulatory LH surge with reduced $\mathrm{GnRH}$ release from the hypothalamus, including insufficient positive feedback.

In conclusion, a decrease in the expression of ovarian $C R$ with ageing is associated with the decrease in the function of theca-interstitial cells, and the expression of the enzyme is directly stimulated by the increase in LH rather than FSH in aged rats at persistent oestrus.

\section{References}

Aono T, Kitamura Y, Fukuda S and Matsumoto K (1981) Localization of 4-ene-5 $\alpha$-reductase, $17 \beta$-ol-dehydrogenase and aromatase in immature rat ovary Journal of Steroid Biochemistry 14 1369-1377

Inazu $\mathbf{N}$ and Satoh T (1994a) Activation by human chorionic gonadotropin of ovarian carbonyl reductase in mature rats exposed in vivo to estrogens Biochemical Pharmacology 47 1489-1496

Inazu N, Inaba N and Satoh T (1989) Localization and regulation of ovarian carbonyl reductase in rats Progress in Clinical and Biological Research 290 32.3-3.34

Inazu N, Inaba N and Satoh T (1990a) Regulation of ovarian carbonyl reductase mediated by estrogen receptor in immature rats Biochemical Pharmacology 40 2495-2502

Inazu N, Inaba N and Satoh T (1990b) Immunohistochemical localization and physiological regulation of carbonyl reductase in immature rat ovary The Japanese Journal of Pharnacology 54 113-121

Inazu N, Iwata N and Satoh T (1990c) Inhibitory effect of glucocorticoid and stimulatory effect of human chorionic gonadotropin on ovarian carbonyl reductase in rats Life Sciences $\mathbf{4 6} 841-848$

Inazu N, Ruepp B, Wirth H and Wermuth B (1992a) Carbonyl reductase from human testis: purification and comparison with carbonyl reductase from human brain and rat testis Biochimica et Bioplysica Acta 1116 $50-56$

Inazu N, Inaba N, Satoh T and Fujii T (1992b) Human chorionic gonadotropin causes an estrogen-mediated induction of rat ovarian carbonyl reductase Life Sciences 51 817-822

Inazu N, Nagashima Y, Satoh T and Fujii T (1994) Purification and properties of six aldo-keto reductases from rat adrenal gland Journal of Biochemistry (Tokyo) 11599 I-999

Iwata N, Inazu N and Satoh T (1989) The purification and properties of NADPH-dependent carbonyl reductases from rat ovary journal of Biochemistry (Tokyo) 105 556-564 
Iwata N, Inazu N, Takeo S and Satoh T (1990a) Carbonyl reductases from rat testis and vas deferens European Journal of Biochemistry 193 75-81

Iwata N, Inazu N and Satoh T (1990b) Immunological and enzymological localization of carbonyl reductase in ovary and liver of various species Joumal of Biochemistry (Tokyo) 107 209-212

Iwata N, Inazu N and Satoh T (1990c) Changes in rat ovarian carbonyl reductase activity and content during the estrous cycle, and localization Biology of Reproduction 42 161-166

Lowry OH, Rosebrough NJ, Farr AL and Randall RJ (1951) Protein measurement with the Folin phenol reagent Journal of Biological Chemistry 193 265-275

Matt DW, Coquelin AW and Lu JKH (1987) Neuroendocrine control of luteinizing hormone secretion and reproductive function in spontaneously persistent-estrous aging rats Biology of Reproduction 37 1198-1206

Meites J (1982) Changes in neuroendocrine control of anterior pituitary function during aging Neuroendocrinology 34 15I-156
Merchenthaler I, Lengvari I, Horrath J and Setalo G (1980) Immunohistochemical study of the LHRH-synthesizing neuron system of aged female rats $C_{e} l l$ and Tissue Research 209 499-503

Rubin BS (1992) Isolated hypothalami from aging female rats do not exhibit reduced basal or potassium-stimulated secretion of luteinizing hormonereleasing hormone Biology of Reproduction $47254-261$

Rubin BS, King JC and Bridges RS (1984) Immunoreactive forms of luteinizing hormone-releasing hormone in the brain of aging rats exhibiting persistent vaginal estrus Biology of Reproduction 31 343-351

Scarbrough K and Wise PM (1990) Age-related changes in pulsatile luteinizing hormone release precede the transition to estrous acyclicity and depend upon estrous cycle history Endocrinology 126 884-890

Wermuth B (1985) Aldo-keto reductases Progress in Clinical and Biological Research 174 209-230 